Article

\title{
Let the Game Begin: Enhancing Sustainable Collaboration among Actors in Innovation Ecosystems in a Playful Way
}

\author{
Anastasia Roukouni ${ }^{1, *}$, Heide Lukosch ${ }^{2}$, Alexander Verbraeck ${ }^{3}\left[\right.$ and Rob Zuidwijk ${ }^{4}$ (D) \\ 1 Faculty of Civil Engineering \& Geosciences, Delft University of Technology, Stevinweg 1, \\ 2628 CN Delft, The Netherlands \\ 2 HIT Lab NZ, University of Canterbury, 69 Creyke Road, Christchurch 8041, New Zealand; \\ heide.lukosch@canterbury.ac.nz \\ 3 Faculty of Technology, Policy and Management, Delft University of Technology, Jaffalaan 5, \\ 2628 BX Delft, The Netherlands; a.verbraeck@tudelft.nl \\ 4 Rotterdam School of Management, Erasmus University Rotterdam, Burgemeester Oudlaan 50, \\ 3062 PA Rotterdam, The Netherlands; rzuidwijk@rsm.nl \\ * Correspondence: a.roukouni@tudelft.nl; Tel.: +31-613248875
}

Received: 18 September 2020; Accepted: 10 October 2020; Published: 15 October 2020

\begin{abstract}
Logistics and transport systems are complex systems for which sustainable innovations are urgently needed. Serious games are an acknowledged tool for training, learning, and decision making, as well as for helping to introduce innovative concepts for complex systems. Technological innovations for the transport domain that can improve sustainability are usually heavily dependent on the collaboration among actors. A simulation gaming approach can help these actors in understanding the challenges involved, and in finding solutions in a playful, interactive way. Our research approach includes a thorough literature review on games for innovation and collaboration in transport networks, and the development of two dedicated simulation games addressing sustainability innovations for the Port of Rotterdam, the largest seaport in Europe and one of the largest in the world. The two innovation cases are truck platooning and multi-sided digital platforms for barge transportation, both improving the sustainability of hinterland transportation. The games serve as instruments to reveal interactions and tensions among actors, contribute to the interpretation of their behavior, and eventually help all parties to reach a better understanding on how innovation adoption can be fostered, using an innovation ecosystem perspective. We are convinced that serious gaming, by providing a better understanding of the innovation process, will help the implementation of sustainability innovations in complex systems.
\end{abstract}

Keywords: transport networks; logistics; simulation games; serious games; innovation ecosystem; Port of Rotterdam; complex systems; truck platooning; barge transport; multi-sided platforms

\section{Introduction}

Bridging the gap between the conception and introduction of an innovation in the context of research and development, and its effective adaptation and diffusion in an industry is a challenge that many sectors are currently facing [1-3]. The development of a technical innovation can be much faster than the capacity of organizations to implement it. For example, sensors used by vehicles to scan their environment are technically very mature, yet the implementation of sensor technology on our streets is still hindered by a lack of investment, trust, and cooperation of actors. The transport and logistics sector is no exception in experiencing a gap between development and implementation of technological innovations [4]. The sector includes a large number of interconnected actors, being highly dynamic 
and complex [5], which makes the implementation of innovations quite challenging. Nonetheless, the transport and logistics sector is in desperate need for innovations, especially to reduce emissions while offering competitive services, and shift towards more sustainable practices in general.

Transport and logistics communities often consider the adoption of innovative business models as an effective means to enable their participation in a sustainable, agile and collaborative logistics and transportation system. This can involve accelerating the digitization of the sector to enhance supply chain visibility as well as data quality and reliability, often by the use of multi-sided digital platforms [6].

Meanwhile, the concept of an "innovation ecosystem" has recently evolved as a new way to approach and promote innovation [7,8]. An innovation ecosystem is defined as a system in which continuous and dynamic interactions among different actors occur, therefore innovation is not realized as a result of individual efforts but as the outcome of multifaceted communication and synergies among the actors $[9,10]$. These actors should become aware of the opportunities and risks of technological innovations. Simulation games are evolving, at an accelerated pace, into a recognized means to endorse learning processes in an intriguing setting, that invites diverse actors to work with one another actively towards common goals [11]. They represent a widely accepted instrument in the transportation and logistics domain for many years already [12].

The research presented in this paper attempts to connect the aforementioned topics. The research questions on which our work is based are: (1) Can simulation games be used as an instrument to comprehend the underlying forces around innovation processes in transport and logistics using an "innovation ecosystem" perspective? (2) Can they be used as a means to facilitate knowledge transfer of innovation from theory to practice and contribute in exploring the roles of different actors involved?

The research approach to answer these questions is built around two serious board games that have been developed to study the role of collaboration among stakeholders in the field of transport, logistics and supply chain management towards the effective implementation of innovations. Mobinn (Mobilize Innovation), the first game, is tailored to the case of truck platooning, an innovation to increase sustainability for truck transport that is mature in terms of developed technology, yet unfledged when it comes to implementation. After testing this game through several game sessions, a second game has been developed: Platform4Barge: a Mobinn game. The lessons learnt from the first game have been incorporated into this new version which focuses on another important component of the transport network; the introduction of multi-sided digital platforms and its impact on port environments, especially on barge transport, which is a more sustainable transport means than truck transport when utilized well. Both games are aimed to raise awareness for the challenges that come with implementing such innovative systems, to ensure a viable implementation pathway. Such games can be seen as novel approaches allowing stakeholders to pre-experience future technology effects, which go beyond verbal descriptions or abstract representations [13].

The remainder of this paper is structured as follows: The literature review section provides an overview of the concept of innovation ecosystems, followed by an overview of existing game approaches towards innovation with a focus on transport and logistics. After that, the case context is presented, with insights regarding the challenges faced by actors in port environments, when it comes to introducing truck platooning or multi-sided digital platforms. The two serious games that have been developed are introduced and described in the next section, followed by the results and discussion section that is based on the outcome of the game sessions that have been organized for both games. The paper concludes with some general guidelines and recommendations regarding the use of serious games to enhance the implementation process of innovations in transport and logistics.

\section{Literature Review}

\subsection{Overview of the Concept of Innovation Ecosystems}

The idea that innovation is a continuous process, seen more as a journey in time rather than several events that takes place at specific moments is one of the core concepts in innovation management [14]. 
It has been found that the impact of innovation can also be wider when it is examined as a continuous process rather than a series of discrete events [15]. Innovation can thus be defined as a process through which novel solutions emerge as multiple actors interact and exchange resources to co-create value [16]. Innovation relies upon a complex network of actors and activities, which can be rather heterogeneous [17].

The use of the term ecosystem in a business context was introduced by Moore [18] in his paper of 1993 "Predators and Prey: A New Ecology of Competition", using the similarities he observed between natural ecosystems and the mechanisms related to businesses and innovation as a base for his reasoning. Innovation ecosystems emerge as a result of collaborative interactions, when cooperating actors accomplish a certain level of integration regarding a shared identity, shared strategy and shared objectives [19]. Moreover, an innovation ecosystem stimulates synergies among people and firms in a given geographical space, enhancing the development and commercialization of new ideas [20] and creating and capturing value [21].

Focusing on urban technology innovation ecosystems, Mulas et al. [22], describe these as a number of stakeholders, assets, and the interaction among them in city environments resulting in new technology and ideas. The innovation ecosystem thinking focuses on the creation of social capital and the enhancement of interpersonal relationships which contributes, among others, in the more effective flow of information, financial resources as well as talent worldwide [23]. Under an innovation ecosystem perspective, innovation diffusion is a multi-level and multi-actor phenomenon [2].

According to Su et al. [24], a shift of interest is observed among innovative enterprises lately; they no longer focus on competition in terms of products and services, but in terms of the innovation ecosystems they belong to. Innovation ecosystems vary considerably in terms of their organization and business models, having an impact on the strategic choices made by businesses, both existing and new ones. These choices can shape competition and therefore encourage innovation and eventually transform the innovation ecosystem itself [25].

Nowadays, the nature of government interventions is also changing, moving away from the purely administrative role they used to have. The countries and areas in which government bodies and authorities of all levels introduce new functional roles of facilitators and intermediators for collaborative interactions within and among innovation ecosystems appear to provide a competitive advantage in creating and maintaining successful innovation ecosystems [19].

Vasconcelos Gomes et al. [26] aimed to provide an answer to the question how to coordinate a complex network of actors in the presence of individual and collective uncertainties in innovation ecosystems. They conducted a comparative analysis of five case studies; all of them start-ups that created and coordinated complex innovation ecosystems for the development and commercialization of radical innovations. They found that many actors in an innovation ecosystem tend to initially consider uncertainties more as individual uncertainties without realizing that other partners may also face the same kind of uncertainty. Moreover, when trying to mitigate or overcome these uncertainties in an isolated way, without taking into account the innovation system partners, they may contribute to the diffusion of those uncertainties through the innovation ecosystem; this way, a specific uncertainty that begins as individual is then integrated into the mindset and decision planning of different actors, hence becoming collective.

Lubik and Garnsey [27] claimed that under an innovation ecosystem perspective is it obvious that value generation is a dispersed process which encompasses co-innovation from other actors in the business environment who have the potential to increase the generated value. In addition to that, according to Pellinen et al. [28], in a business ecosystem, the process of decision making can be influenced by actions, as well as expectations of other actors in the same ecosystem, through a pattern of co-evolution.

Focusing on the logistics sector, Meyer-Larsen et al. [29] emphasize the importance of creating innovation ecosystems; they state that the increase of interaction among the different actors involved is expected to limit the existence of trust issues which could result also in the faster adoption of innovation 
and help overcome existing barriers. In the relevant literature it is increasingly mentioned that a better understanding of the roles that the different ecosystem actors play in the innovation process should be obtained (e.g., see $[14,30])$.

In summary, we can see that the innovation ecosystem perspective is one that allows us to look at innovation in a connected way, including actors and their relationships, as well as concerted actions towards innovation implementation. We take over this perspective for the transfer of innovation into a game model used to make actors aware of challenges related to innovation implementation in a sustainable way. In the next section, we describe the instrument of serious games in the domain of transport and logistics to help us define our gaming approach.

\subsection{Overview of the Use of Games in Transport, Logistics and Innovation}

Serious games are used more and more to enhance awareness and encourage the process of knowledge building in an engaging environment that invites collaboration among different stakeholders [11]. Although the term may sound relatively new, in reality serious games is just a modern expression of approaches and models which date back many centuries ago [31]. The process of playing is inherently connected with human societies, all over the world. In ancient Greece for instance, Plato was the first philosopher who emphasized the educational importance of games in formulating children's attitude; he claimed that through games, children are given the opportunity to get familiarized with habits that are going to be useful for them for the rest of their life [32].

Clark Abt, in his book Serious Games (1970) [33], gave a definition of what makes a game be characterized as a serious game. According to this definition, serious games "have an explicit and carefully thought-out educational purpose and are not intended to be played primarily for amusement. This does not mean that serious games are not, or should not be, entertaining" [33] (p. 9). A few years later, Duke estimated that games were going to be the language of the future and published the homonymous book Gaming: The Future's Language [34]. Approximately half a century later, numerous definitions can be found in relevant literature, from different researchers in different scientific areas and fields. In our research, serious games or simulation games are synonymous and can be described as "experimental, rule-based, interactive environments, where players learn by taking actions and by experiencing their effects through feedback mechanisms that are deliberately built into and around the game" [35] (p. 825).

Serious games use a simplified abstracted model of reality, contributing this way to a better understanding of complex issues [36]. Having a set of clearly defined rules, they encourage interaction, while at the same time providing a model for learning. Moreover, the direct consequences of every action and decision can be observed, therefore the players can realize the impact of their own decisions, as well as of the ones of the other players [37], within a "safe" environment [35]. These characteristics make them valuable tools for exploration and observation of player behavior.

According to Olejniczak et al. [38], the use of serious games by policy makers is a very promising approach in estimating the impact of new complex policies and regulations, due to the fact that they comprise the following strengths:

- They are able to reveal mechanisms such as the initial assumptions of the stakeholders involved, their decisions, as well as the feedback loops that are created by their reactions;

- They demonstrate the effects of these mechanisms over time, which in real life becomes evident over a much longer period, and;

- They create a risk-free environment in which the representatives of the different actors can test hypothetical scenarios of different policies and experiment with new ways of interpreting these and similar actions.

In supply chain management, simulation games have been used to bring attention to the topic of shared resources [29]. When simulation games are employed, the ideas generated to overcome barriers related to innovation implementation tend to be more creative [39], and the impacts of applications 
which are based on information communication technologies (ICT) or intelligent transportation systems (ITS) can be examined effectively through them [40]. Simulation games can also be used as an efficient channel for information provision around future situations, associated with a high level of uncertainty, such as climate change [41]. Hidayatno et al. [42] designed a serious simulation game to act as a learning medium of supply chain management for biofuel production. Their game focuses on companies which operate crude palm oil mills. According to the authors the game has proven to be effective in increasing the understanding of players on concepts and complex issues related to sustainable supply chain management. With the learning objective of this game focusing on internal material flow, another simulation game was developed, under the objective of making players familiar with the important role that Industry 4.0 technology can play in production logistics [43].

Focusing on the Dutch railway system, Van den Hoogen and Meijer [44], found that simulation gaming can contribute to the coordinated planning of innovation implementation. Kurapati et al. [45], examined how simulation games can be used to foster sustainability in transportation operations through synchromodal corridor management. The authors developed a digital simulation game which was tested in game sessions with experts in The Netherlands.

Simulation gaming can be thus considered as a robust approach increasing comprehension in large-scale systems with a high degree of integration and with numerous actors dealing with significant uncertainties [36], by examining these systems through different perspectives [46].

\section{Case Analysis-Context of the Game-Based Research Studies}

Port cities around the world have the increasing tendency to be engaged in various strategies to stimulate innovation through activities such as triple-helix collaborations, innovation ecosystem approaches, urban entrepreneurialism etc. [47].

The city of Rotterdam in The Netherlands is home to the Port of Rotterdam, being the largest container seaport in Europe and 10th largest in the world with state-of-the-art container terminals [48]. In 2019, the total number of deep-sea vessels that docked in the Port exceeded 29,000 and that of inland vessels reached approximately 86,000 [48]. This is translated to almost 8.8 million containers (more than 14.8 million TEU (TEU: "twenty-foot equivalent unit. This is the standard unit for counting containers of various capacities and for describing the capacities of container ships or terminals. One 20 foot ISO (International Organization for Standardization) container equals 1 TEU") [49]).

In 2011, Rotterdam Port Authority, in collaboration with various ministries, businesses and research institutes in The Netherlands, published a strategic development plan called 'Port Vision $2030^{\prime}$, in which comprehensive strategies to handle the growing volumes of containers in an efficient and sustainable way were presented. In this vision document, it was stated that by 2030 the aim would be to drastically reduce the road share of hinterland container transport, reaching $35 \%$, so that $65 \%$ of containers would be transported by barge or rail [50].

It is undeniable that in terms of transport and logistics, The Netherlands has many unique location advantages among European countries with the Port of Rotterdam being a major multi-modal gateway to the rest of Europe. As a result, as already highlighted in Roukouni et al. [51], a huge strain is put on the road network, while the demand keeps increasing and there is a drastic need for innovations that make use of the current infrastructure more efficiently and reduce congestion, while at the same time enhance traffic safety and limit transport emissions [52]. One promising case to deal with these challenges is truck platooning [51].

Truck platooning can be defined as the concept of "trucks driving automatically in small convoys, a short distance apart, using wireless vehicle-to-vehicle (V2V) communication and advanced driver assistance systems resulting in a smoother traffic flow, higher traffic safety, fuel savings and a reduction in $\mathrm{CO}_{2}$ emissions" [53] (for more information about the ruck platooning concept see [54,55]). According to Roukouni et al. [51], "for the truck platooning concept to work, many factors have to be aligned, e.g., the technology has to be developed, the legislation and road infrastructure have to be adapted, and the business model has to be accepted by the users". Hence, although the technology has been evolving a 
lot during the last years, there is still a way to go as certain technological barriers exist, in addition to a conservative attitude of several of the logistics companies involved. Moreover, as multiple actors are involved, there are a lot of stakeholders that have to align in order for the final decisions to be taken. Therefore, it is obvious that truck platooning has all the characteristics of a complex system and represents a sustainable innovation on the forefront of development in The Netherlands $[51,56]$. All these reasons made it an ideal choice for a demonstration case for the development of our first serious board game, Mobinn.

At the same time, the large and continuously growing volume of containers being transported through the Port of Rotterdam also creates a need for other innovative systems, such as a digital platform that would gather all the required information for booking containers into one single place. Multi-sided platforms (MSP) are "technologies, products or services that create value primarily by enabling direct interactions between two or more distinct customer or participant groups" [57]. The tremendous technological progress of our era, facilitated platform development and lead to an unprecedented volume of data exchange, which magnifies the platform's value for all the parties involved, often resulting in disrupting sectors as a whole, as in the case of Uber or Airbnb platforms for example [51,58].

The potential scalability of digital platforms is a reason why they can cause such disruptions. They cause network effects which can be either positive, resulting to additional value, or negative, having the exact opposite result [59]. A key factor to improving visibility in supply chains and transport networks is information sharing [60]. However, many companies and actors are reluctant to share information as they assume the power of information is diminished when it is shared [61]. Olesen et al. [62] found that the lack of information exchange usually has three causes; limited data availability, lack of trust and system complexity. Being aware of the existence of these challenges, we decided to develop the second serious game, Platform4Barge, to increase actors' awareness of the importance of data sharing and transport network visibility for inland barge transport, which is seen, together with rail, as the sustainable replacement for truck transport.

\section{Development of the Serious Games}

Serious games represent an interactive and efficient instrument for learning, decision-making, and awareness building and they are an effective tool for simulating dynamic and complex systems, such as transport and logistics systems [35,36]. While the sector has successfully implemented game-based approaches to address several challenges already (see e.g., $[44,45,63,64]$ ), the question of innovation implementation has not yet been addressed thoroughly through a game-based approach. Below, we explain how the two games, based on the two illustrated cases, have been designed in order to fill this gap.

\subsection{Elements and Game Play}

The Mobinn (Mobilize Innovation) game is a board game that represents the relationships among actors involved in setting up a truck platoon in a simplified way. Platform4Barge is a second version of the initial game, which has been tailored to the specific situation and challenges around the use of multi-sided digital platforms in barge transportation. The two games were developed based on an iterative process that used loops of testing and adjustments of early prototypes, and included researchers, game developers, and domain experts.

We followed the philosophy of the triadic game design (TGD) concept, introduced by Harteveld [65]. According to the TGD concept, each serious game comprises three different "worlds"-reality, meaning and play. The first one, reality, as the term implies, refers to the world that is surrounding us and to its reflection to the game we are developing. The world of meaning is associated with purposefulness; as we have already discussed previously in Section 2.2 of the article, serious games have certain defined objectives to fulfil, such as creating awareness towards a specific issue etc. A serious game does not exist just to be played and provide entertainment to the participants. At the same time though, 
the component of fun should not be overlooked as well, as it is placed in the center of the third world, the one of play. This world includes also the game elements and dynamics, which are the means that can make the game experience captivating and intriguing for the players [65].

Embracing this game design philosophy, we considered the component of meaning and the component of play the same for both our serious games. Meaning is reflected on the objective of our research, which, as stated previously in the introduction, is to raise awareness around the challenges associated with implementing innovative systems in transport and logistics in a sustainable way and explore the role of different actors involved. The game materials and dynamics also do not change. The physical game elements of each game include: one game board, four role cards, five action cards per role, event cards, tokens, and pawns. The roles of the players in the two games correspond to the key actors of the truck platooning ecosystem and of the port container ecosystem for Mobinn and Platform4Barge respectively. What changes is the world of reality for the two cases, and thus the content of all the cards involved in each game. A description of how we obtained the critical insights in the reality of each one of the cases, which helped us then unfold the content of the cards, follows.

For the Mobinn game, in order to develop the role cards, as well as the action and event cards of the game, we first needed to understand who are the main actors that are involved in shaping the truck platooning community and what is "at stake" for each one of them; then we translated this information into content of our three types of cards: role cards, action cards and event cards. we started by a comprehensive literature review of scientific papers about truck-platooning (publications in journals and conference proceedings, working papers, theses', e.g., see $[54,55,66])$. As truck platooning, being a technology-driven innovation, does not have such a large volume of scientific literature available yet, we also decided to study materials such as white papers, reports (e.g., see [52,67], websites and media sources e.g., see $[68,69]$. Moreover, The Netherlands has organized a few years ago the so-called European Truck Platooning Challenge, when the country was in the EU presidency [70], and we also reviewed the results of this initiative [71,72]. After the online desk research which helped us obtain a better understanding of the truck platooning world and especially of the actors involved, we discussed our initial ideas with actors within the Port of Rotterdam and we concluded that the main categories of actors involved in truck platooning are the following: the transporters, the freight forwarders, the policy-makers and the developers.

Each actor category then helped us in building a role and creating a role card that "brings this role into life"-from the world of reality into the world of play. Each role card briefly explains who the player is and what is his/her mission in the game. For instance, the developer is a representative of an original equipment manufacturer (OEM) company, which is interested in the truck platooning technology and has already invested a significant amount of resources in the research and development process. The objective of this role is to develop the technology before the company's competitors in the field in the most cost-effective way possible. The absence of EU regulations on the topic is a source of concern for this role. The policy-maker's role in the game is represented by an employee with a high-ranking position in the Dutch Ministry of Infrastructure and Water Management. The main dilemma that this role faces is if they should be patient until the EU publishes regulations and then align the national policy accordingly or work towards making The Netherlands a frontrunner country in this field, by introducing country-level policy that would encourage the deployment of truck-platooning. Figure 1a illustrates an example of a role card in Mobinn.

In the case of Platform4Barge, to re-construct the world of reality around it, we followed exactly the same logic in developing the game cards' content; beginning with a thorough literature review on the field of multi-sided digital platforms, with a focus on digital platforms in transport and logistics, and the container ecosystem in particular. As an extra way to gain meaningful insights in this case, we used also our experience from co-developing a set of four teaching cases and a teaching note around the use of multi-sided digital platforms in transport and logistics [73], together with actors from the Port of Rotterdam as well as from the private sector (we worked on the cases' development in parallel with the game development). We organized a number of try-out sessions with master's 
students in Rotterdam to test and validate the teaching cases, and the feedback we received was also valuable content wise for the development of the game cards. Following that, we arranged meetings with actors of the Port of Rotterdam who helped us in shaping our ideas and finally deciding the four main categories of actors for this game: the shippers/freight forwarders (in a combined role that represents the demand side), the deep-sea terminal operators, the barge operators and the port authority. For example, the role card of the representative of the port authority implies that the player acts as an orchestrator of the introduction of the digital platform and its operation and as a facilitator of the process. Achieving sustainability through modal shift is of crucial importance for this actor. Figure $1 \mathrm{~b}$ presents an example of a role card in Platform4Barge.

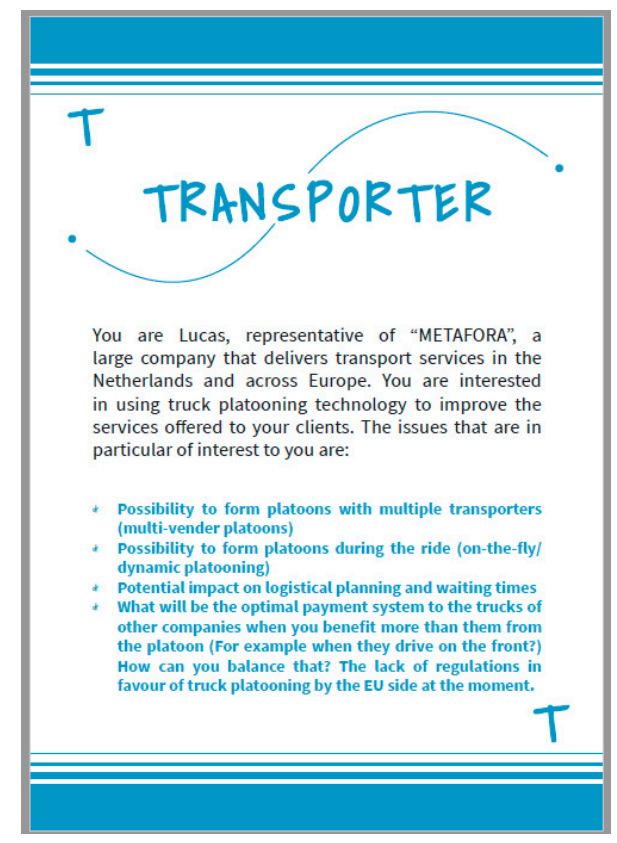

(a)

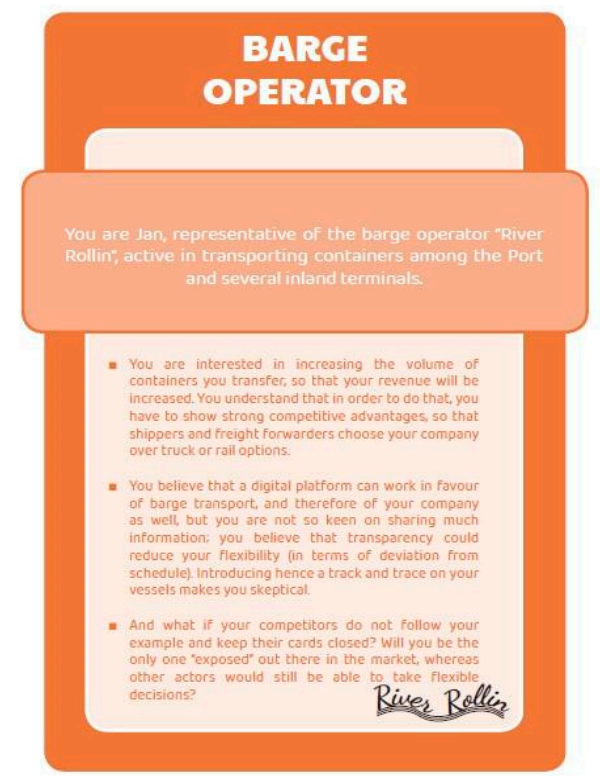

(b)

Figure 1. Example of a role card in: (a) Mobinn and; (b) Platform4Barge.

The same process of exploring the world of reality for both our case studies, helped us also in defining the key performance indicators (KPIs) for both the games, as illustrated in Table 1.

Table 1. Key Performance Indicators of Mobinn and Platform4Barge.

\begin{tabular}{ll}
\hline Mobinn & Platform4Barge \\
\hline Technology maturity & Modal shift \\
Physical/legal infrastructure maturity & Reliability \\
Innovation adoption & Innovation adoption \\
\hline
\end{tabular}

The KPIs are illustrated on the game boards, with a 1-9 point scale, using a "traffic light" approach, i.e., dividing the scale in three areas: red, yellow and green, inspired by the work of Van den Ende (2019) (Figure 2a,b). The green area indicates alignment of interests and goals, the yellow area shows only partial alignment, while the red one demonstrates lack of consensus of actors. Each action card, in addition to describing a certain action that can be performed by a certain role, indicates the number of tokens needed to be paid by this role as well as by other(s) in the game in order to be activated. The impact of the card on the three KPIs of the game is also mentioned (Figure 3a,b). The event cards contribute in creating more suspense and fun during the game, as they can indicate either a positive, or a negative event that "disrupts" the players' plan and can make them adapt their strategy (Figure 4a,b). 


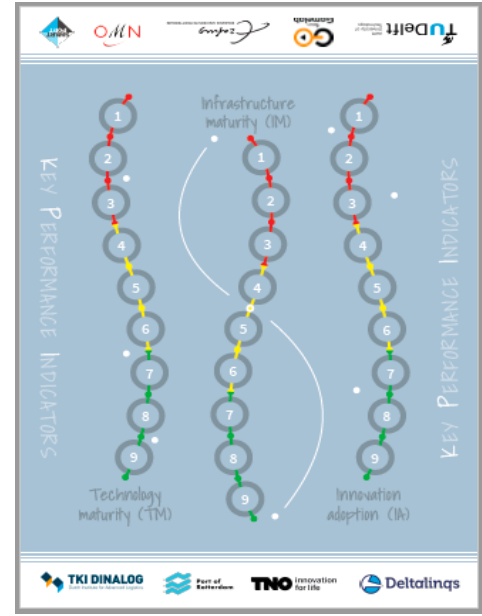

(a)

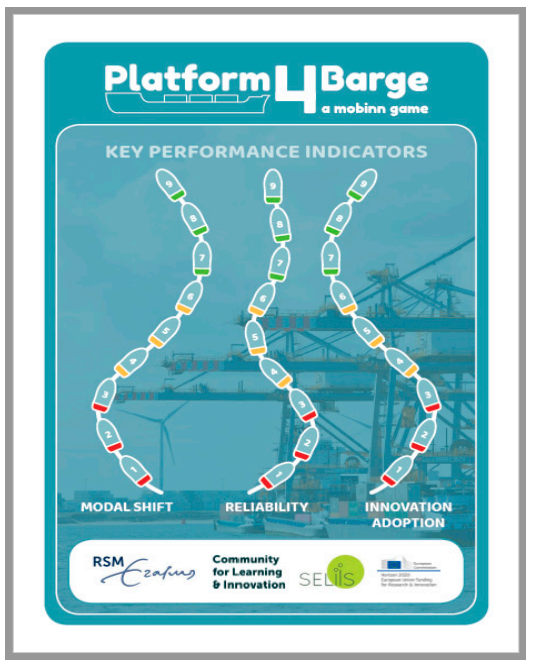

(b)

Figure 2. Game board and key performance indicators (KPIs) in: (a) Mobinn and; (b) Platform4Barge.

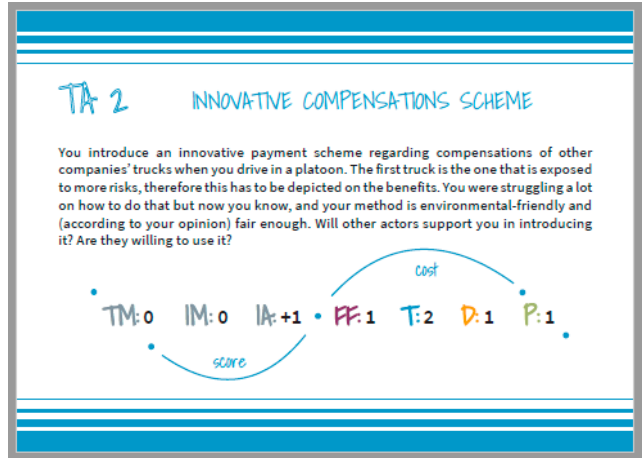

(a)

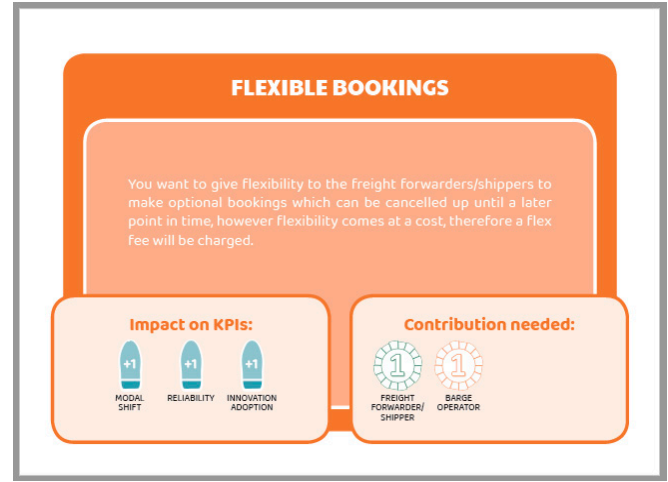

(b)

Figure 3. Example of an action card in: (a) Mobinn and; (b) Platform4Barge.

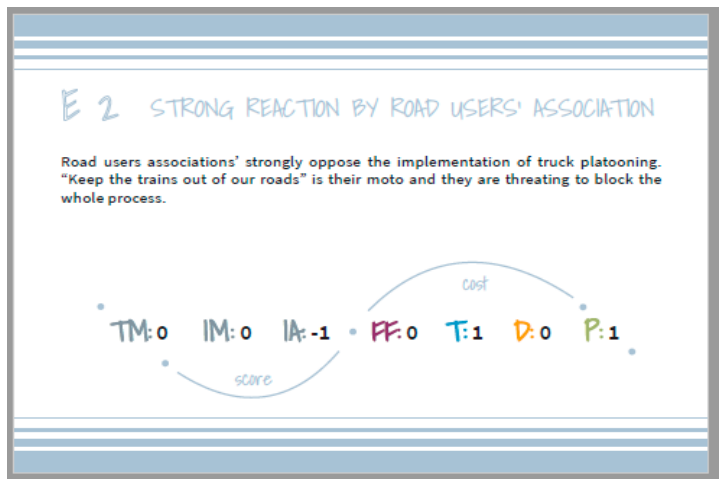

(a)

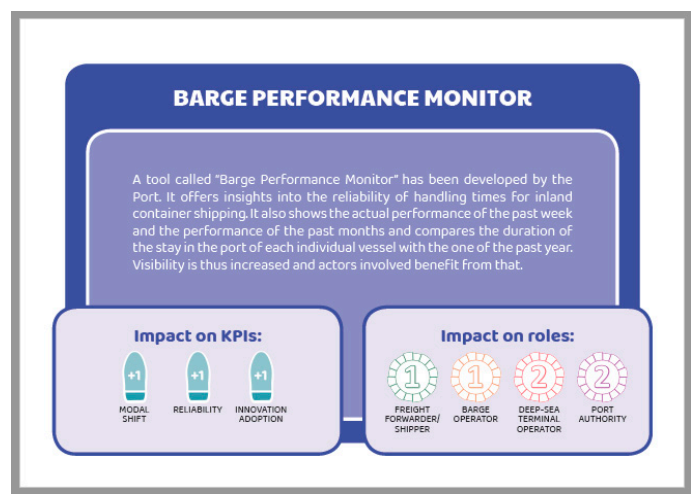

(b)

Figure 4. Example of (a) a negative event card in: Mobinn and; (b) a positive event card in Platform4Barge.

Both games are played in five rounds. At the beginning of a game session, each player gets one role card, all respective actions cards and an initial number of tokens. When a round begins, each player can either bring to the negotiations table one of the action cards or alternatively he/she can choose to not "act" in this round. After every player shares his/her decision, the players who chose to use an action card, simultaneously place them on the board. Each player has to pay the number of 
tokens that is written on the card for his/her own role before requesting other players to support the action with their tokens.

The card is considered valid and has an impact on the KPIs of the game, only in cases when all the roles mentioned on it agree to contribute with the necessary number of tokens-otherwise, the player who suggested the card loses the invested tokens and he/she can keep the card for future use. At the end of each round, an event card is drawn, and each player gets some extra tokens, representing income from their services. The role of other important actors (in addition to the ones represented by the four main roles), such as the European Commission (in the form of regulations or directives), is introduced in the game through the event cards.

The goal of both games is to "make the innovation happen" (in our case the innovation is aimed at the concepts of truck platooning and the multi-sided digital platform respectively), which is translated in achieving to have all three KPIs in the green area of the game board (points 7-9 in the 9-point scale) at the end of game play.

The main learning goal defined for both games is to understand how important an innovation ecosystem perspective is for a successful adoption of innovation in the transportation domain. Actors, decisions and actions within the innovation ecosystem are highly interdependent. Both games aim to highlight this characteristic and make players more aware of the interrelations of decisions and events. The players have the opportunity to influence the innovation ecosystem by (joint) investments and actions, but they must keep in mind that the innovation is also influenced by external events, limited budget and the existence of only five rounds. The game is played by at least four players (one per role). In cases when there are more participants, teams are formed and two or sometimes three players can together play a single role. This enables participants to first discuss choices of actions and it can be seen as a purposeful game element. Every game session is introduced by a short briefing, during which the facilitator explains the concept and the rules of the game. After the completion of the five game rounds, a debriefing follows. The total time of the game play, including briefing and debriefing is approximately 60 to $90 \mathrm{~min}$ for each of the games.

\subsection{Play-Test Sessions and Data Collection}

In order to test the two games and receive valuable feedback for further improvement, several game sessions were organized in which the game prototypes were played. The Mobinn game was tested between October 2018 and November 2019 at game sessions in The Netherlands and the USA (Figure 5a). The Platform4Barge prototype was tested at sessions in The Netherlands between December 2019 and February 2020. (A fourth game session was planned for March 2020, as part of an alumni-student event organized by Transito, the study association for the Bachelor and Master program Urban, Port and Transport Economics (UPTE) of the Erasmus University Rotterdam. This scheduled event was cancelled due to the measures taken to stop the spread of COVID-19 (Corona Virus Disease 2019) in Europe) (Figure 5b).

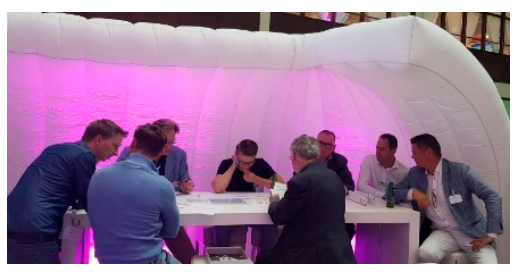

(a)

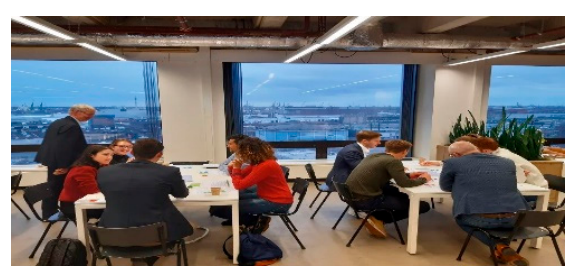

(b)

Figure 5. (a) Play-test session of Mobinn, during the event for the 10th year-anniversary of RDM (Rotterdam Dry Docks, in Dutch: Rotterdamsche Droogdok Maatschappij) Campus in Rotterdam, 4 July 2019; (b) play-test session of Platform4Barge during the Erasmus Port Campus in Rotterdam, 12 December 2019. 
All sessions of both games were facilitated by at least one member of the game development group, who was responsible for the briefing, facilitation, debriefing, as well as for the data collection during and after the game. The data collection took place by audio recording if it was feasible to do so, and by observation through the participating researchers. Usually, one researcher took over the role of process facilitator, and one more observed the session. Beyond dedicated game sessions, the game was also played as part of a larger event, where usually background noise made audio recording difficult. During these sessions, data was collected by observation and notes during the game-play. The notes taken included decisions of the players, the cards they chose to use, as well as their game play behavior. After the end of the game, a debriefing phase was conducted based on semi-structured questions regarding the game experience and the take-aways. (The debriefing questions were adapted from the framework described by Kriz [74], in line with the former adaptation of this framework made for the debriefing and workshops of the Plaitra Game Session, which took place in the context of the iTRACK Project, at TU Delft Campus, The Netherlands, in May 2017). The questions aimed at deriving what types of feelings were experienced by the players during the game play and at revealing the lessons learned (if any) by the game. Moreover, the players were asked what, according to their opinion was working well during the game and which elements might need improvement, and how we can achieve this improvement. These questions were used as a trigger to initiate the discussion with the participants, but they were not in any case exclusive-the players were invited to share any kind of feedback, comment, observation or suggestion for change they considered relevant with the game facilitator. Thus, the debriefing phase focused on the game itself as well as the play experience of the players.

The following tables present the number and type of players, as well as the location where each game session took place (Table 2 for Mobinn and Table 3 for Platform4Barge).

The following section discusses the results of the game sessions.

Table 2. Play-tests sessions that have been organized for Mobinn.

\begin{tabular}{|c|c|c|c|}
\hline Game Session & Number of Players & Type of Players & Location \\
\hline 1 & 5 & $\begin{array}{l}\text { Experts and actors related to the } \\
\text { truck platooning community }\end{array}$ & $\begin{array}{l}\text { Futureland, Maasvlakte II, Port of } \\
\text { Rotterdam, NL }\end{array}$ \\
\hline 2 & 8 & $\begin{array}{l}\text { Transport and logistics experts } \\
\text { from academia and industry }\end{array}$ & $\begin{array}{l}\text { SmartPort (SmartPort is } \\
\text { "a neutral knowledge platform, } \\
\text { stimulating alliances, financing } \\
\text { scientific research and providing } \\
\text { public knowledge dissemination. } \\
\text { The aim is to speed up } \\
\text { innovations in the Port of } \\
\text { Rotterdam" [75] premises, } \\
\text { Rotterdam, NL. }\end{array}$ \\
\hline 3 & 4 & $\begin{array}{l}\text { Researchers in the field of } \\
\text { gaming and/or transportation }\end{array}$ & TPM Faculty, TU Delft, NL \\
\hline 4 & 12 & MBA program students & $\begin{array}{l}\text { Supply Chain Management } \\
\text { Center, Robert H. Smith School of } \\
\text { Business, USA }\end{array}$ \\
\hline 5 & 11 & $\begin{array}{l}\text { Experts in transport and logistics } \\
\text { from the Dutch Railways }\end{array}$ & Railcenter, Amersfoort, NL \\
\hline 6 & 5 & $\begin{array}{l}\text { Actors in the field of transport } \\
\text { and logistics }\end{array}$ & RDM Rotterdam Campus, NL \\
\hline
\end{tabular}


Table 3. Play-tests sessions that have been organized for Platform4Barge.

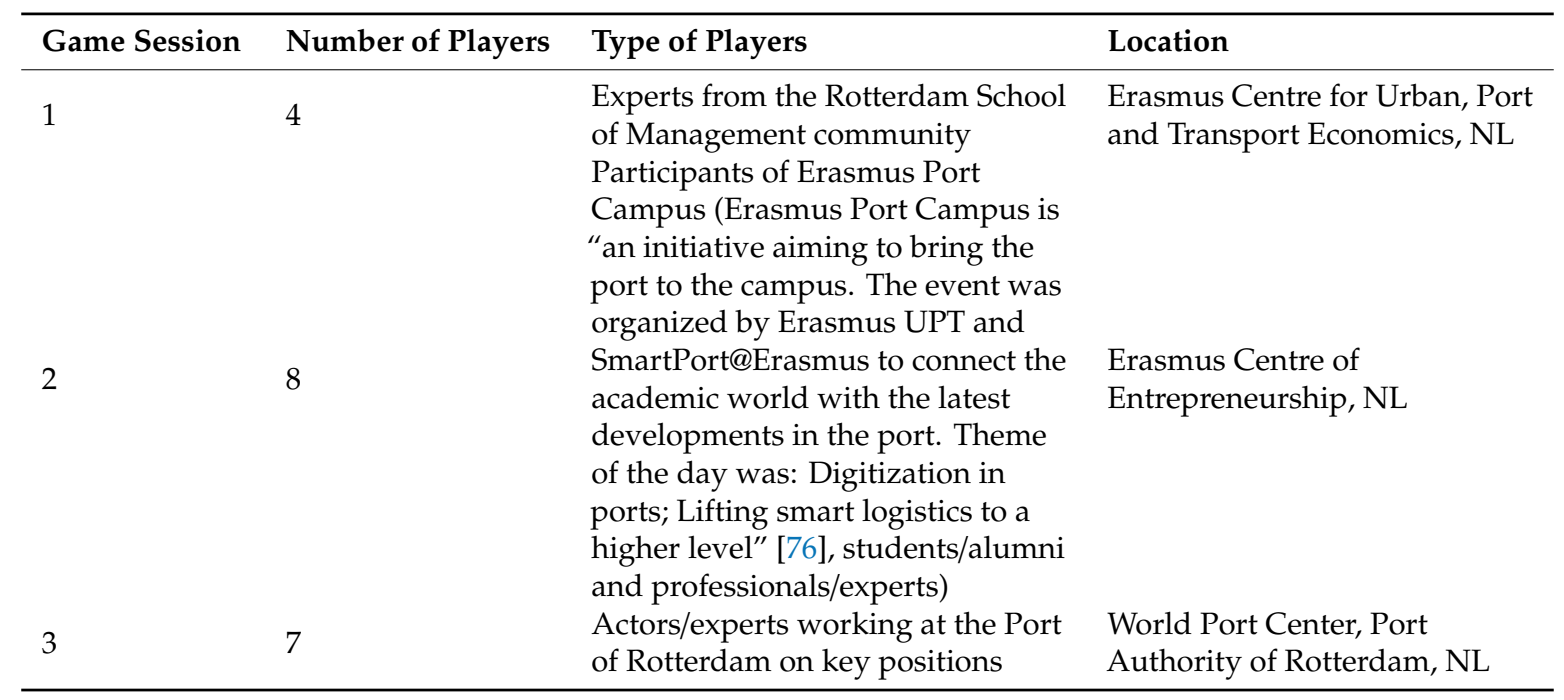

\section{Results and Discussion}

The results discussed in this section represent a summary of the observations of the facilitator and accompanying researcher, collected and analyzed by the researcher team in a qualitative way, based on the in-situ observations during the game play and during the debriefing stage, as well as based on the recordings (when available) and notes for both stages. This approach follows methods as proposed in the field of serious gaming towards solving sustainability-related issues by Den Haan and Van der Voort [77]. Their study found that the majority of publications which fall into the aforementioned category of trying to address sustainability challenges have used qualitative data for the game evaluation, including unstructured observations by the researchers and debriefings.

Both games have been tested by players with a diverse background, knowledge and with different roles; from real actors in the field to professionals and members of the academic and research community; all do have knowledge of the domain of transport and logistics from their respective profession. The facilitator of the game was trying to intervene as little as possible during the game play, to minimize the associated biases and be able to detect and analyze the negotiations and discussions that were taking place among players, and only tried to support the process of play, but not the decision making. High engagement levels were observed during all game sessions, which proved that the games succeeded in creating an enjoyable, comfortable and fun environment for the players.

The negotiations and discussions among players involved more tension when actors with a presence in the field were involved. On the other hand, students and researchers were more curious and keener on learning about the innovation process around truck platooning and multi-sided digital platforms. The professional actors, being already familiar with the concepts, were able to focus more on attributes such as the aspirations of the different roles, and the characteristics of the different actions that could be taken. Students also reported that after the end of the game play, they felt that they obtained a more holistic view and a more comprehensive understanding regarding the challenges for new technologies and innovative concepts to be adopted by the transport and logistics sector. They also realized the value of communication among the stakeholders and organizations in an innovation ecosystem.

As the concept of innovation ecosystem and its importance emerged through the games, the participants appeared afterwards to have realized that nobody can win these games playing alone; it was necessary to discuss, negotiate and collaborate with other parties to increase the KPIs. It was observed that in those game sessions in which the players realized early in time that they needed to collaborate and share information and knowledge with each other to boost the KPIs, almost every game finished with all three KPIs in the green area of the spectrum. On the other hand, in sessions 
where the players appeared more reluctant to collaborate and unwilling to have increased visibility of their negotiation strategy in the beginning of the game, they struggled towards the end of the game and often failed to reach the objective of having all KPIs in the green area within the five rounds of the game.

A very interesting observation was made during a Mobinn game session with real actors related to the Port of Rotterdam; at one of the rounds, the resources of one player/role were not enough to invest in an action card that that player would like to use. At that moment, another player suggested to pay his part instead, because he said that this action could really contribute to the direction of "making the innovation happen" and thus it would be a win-win for both the roles they represented if they made this joint investment. The noteworthy point here is that this was never mentioned in the game instructions as an option, but the game play motivated the creative, out-of-the box thinking of the player towards the direction of collaboration.

When players had already some background knowledge on truck platooning, they considered it a plus in better understanding the Mobinn game. As for Platform4Barge, even players which did not have any background knowledge on the specific topic of exchange platforms, did not encounter difficulties in understanding, because they were familiar with the concept of digital multi-sided platforms through very widespread platforms of this kind in other sectors, such as Uber and other on-demand transport services for shared mobility, and Airbnb in housing.

A repeated comment during the Mobinn sessions was about the equal distribution of money (tokens) among roles; several players felt that this is often not the case in real-life, as the authorities' budget is usually considerably higher than the one of private actors. For this reason, for Platform4Barge it was decided to start with a different number of tokens per role to better reflect the situation in reality.

Last but not least, feedback from experts included the view that identifying all actors involved in an innovation ecosystem, along with their potential actions, is already a very powerful characteristic of both the games.

\section{Conclusions}

Actors from diverse backgrounds participated in a number of play sessions with both games; from experts who represented the real actors in the field, to students, researchers and professionals. This led to very interesting observations and proved that both games can act as triggers to make participants aware of the existing challenges that stakeholders involved in transport and logistics face when implementing innovations to increase sustainability. The games provide useful insights in the benefits of collective goal setting and can support and stimulate discussions towards the importance of collaborative action in innovation processes. The games can be used to trigger a valuable discussion and make actors aware of the value of an innovation ecosystem, and the need for collaboration to achieve sustainability goals.

The results of the game sessions highlight the critical role that each actor can play in an innovation ecosystem, by collaborating on data sharing and improving data visibility and transparency. The study found that using serious games to address the challenge of enhancing awareness, communication and collaboration of actors in innovation ecosystems can be highly effective.

Author Contributions: Conceptualization, A.R., H.L., A.V. and R.Z.; methodology, A.R., H.L., A.V. and R.Z. validation, A.R., H.L., A.V. and R.Z.; formal analysis, A.R., H.L., A.V. and R.Z.; investigation, A.R., H.L., A.V. and R.Z.; resources, A.R., H.L., A.V. and R.Z.; data curation, A.R., H.L., A.V. and R.Z.; writing一original draft preparation, A.R., H.L., A.V. and R.Z.; writing-review and editing, A.R., H.L., A.V. and R.Z.; visualization, A.R., H.L., A.V. and R.Z.; supervision, H.L., A.V. and R.Z.; project administration, H.L., A.V. and R.Z.; funding acquisition, H.L., A.V. and R.Z. All authors have read and agreed to the published version of the manuscript.

Funding: Mobinn game was developed as part of the InDeep (Innovation Network Design Enables Excellent Ports) project, funded by The Netherlands Organization for Scientific Research (NWO). The initial version of the Platform4Barge game was developed in the context of the EU Horizon2020 Project SELIS (Towards a Shared European Logistics Intelligent Information Space). The final version was developed in the context of the project "Digital Platforms for Logistics: Flipping the Classroom by Means of Games and Teaching Cases", funded by the Community for Learning and Innovation (CLI) of Erasmus University Rotterdam as an Educational Innovation project. 
Acknowledgments: The authors would like to thank the lead developers that were involved in the development of the two games. In the case of Platforrm4Barge, in addition to the authors this includes Donald Baan, Arco Jansen and Maurice Jansen. Game production and visual design was realised by the TU Delft GameLab: for Mobinn, by Linda van Veen and for Platform4Barge, by Linda van Veen and Resy Arts. The authors would also like to thank all the participants of the game sessions for their time and valuable feedback on the game and the anonymous reviewers who helped in improving the manuscript by providing their constructive suggestions and comments.

Conflicts of Interest: The authors declare no conflict of interest. The funders had no role in the design of the study; in the collection, analyses, or interpretation of data; in the writing of the manuscript, or in the decision to publish the results.

\section{References}

1. United Nations Department of Economic and Social Affairs. World Economic and Social Survey 2018: Frontier Technologies for Sustainable Development; United Nations Department of Economic and Social Affairs: New York, NY, USA, 2018; ISBN 9789211091793.

2. Trischler, J.; Johnson, M.; Kristensson, P. A service ecosystem perspective on the diffusion of sustainability-oriented user innovations. J. Bus. Res. 2020, 116, 552-560. [CrossRef]

3. Gruenhagen, J.H.; Parker, R. Factors driving or impeding the diffusion and adoption of innovation in mining: A systematic review of the literature. Resour. Policy 2020, 65, 101540. [CrossRef]

4. Acciaro, M.; Sys, C. Innovation in the maritime sector: Aligning strategy with outcomes. Marit. Policy Manag. 2020, 1-19. [CrossRef]

5. Nilsson, F.R. A complexity perspective on logistics management: Rethinking assumptions for the sustainability era. Int. J. Logist. Manag. 2019, 30, 681-698. [CrossRef]

6. Roukouni, A.; Zuidwijk, R. Port of Rotterdam: Booking.com for Container Transport; Erasmus Research Institute of Management, RSM Case Development Centre: Rotterdam, The Netherlands, 2020; pp. 1-14.

7. Liu, Z.; Stephens, V. Exploring innovation ecosystem from the perspective of sustainability: Towards a conceptual framework. J. Open Innov. Technol. Mark. Complex. 2019, 5, 48. [CrossRef]

8. Bacon, E.; Williams, M.D.; Davies, G. Coopetition in innovation ecosystems: A comparative analysis of knowledge transfer configurations. J. Bus. Res. 2020, 115, 307-316. [CrossRef]

9. Toshiyuki, K.; Kazuaki, K. An institutional approach to the creation of innovation ecosystems and the role of law. Penn St. JL Int'l Aff. 2015, 4, 167.

10. Smorodinskaya, N.; Russell, M.; Katukov, D.; Still, K. Innovation Ecosystems vs. Innovation Systems in Terms of Collaboration and Co-creation of Value. In Proceedings of the 50th Hawaii International Conference on System Sciences, Waikoloa Village, HI, USA, 4-7 January 2017. [CrossRef]

11. Agogué, M.; Levillain, K.; Hooge, S. Gamification of Creativity: Exploring the Usefulness of Serious Games for Ideation. Creat. Innov. Manag. 2015, 24, 415-429. [CrossRef]

12. Raghothama, J.; Meijer, S.A. A Review of Gaming Simulation in Transportation. In Proceedings of the Frontiers in Gaming Simulation. ISAGA 2013. Lecture Notes in Computer Science; Springer: Berlin/Heidelberg, Germany, 2014.

13. Midden, C.; McCalley, T.; Ham, J.; Zaalberg, R. Using persuasive technology to encourage sustainable behavior. In Proceedings of the 6th International Conference on Pervasive Computing, Workshop on Pervasive Persuasive Technology and Environmental Sustainability, Sydney, Australia, 19 May 2008; Volume 113, pp. 83-86.

14. Bessant, J.; Rush, H.; Gray, W.; Hoffman, K.; Ramalingam, B.; Marshall, N. Development D. for I. Innovation Management, Innovation Ecosystems and Humanitarian Innovation; University of Brighton: Brighton, UK, 2014.

15. Duncan, L. Innovation as an ongoing process: Developing creative capabilities. Strateg. Dir. 2014, 30, 13-15. [CrossRef]

16. Vargo, S.L.; Akaka, M.A.; Wieland, H. Rethinking the process of diffusion in innovation: A service-ecosystems and institutional perspective. J. Bus. Res. 2020, 116, 526-534. [CrossRef]

17. Corsaro, D.; Cantù, C.; Tunisini, A. Actors' Heterogeneity in Innovation Networks. Ind. Mark. Manag. 2012, 41, 780-789. [CrossRef]

18. Moore, J.F. Predators and Prey: A New Ecology of competition. Harv. Bus. Rev. 1993, 71, 75-83. [PubMed]

19. Russell, M.G.; Smorodinskaya, N.V. Leveraging complexity for ecosystemic innovation. Technol. Forecast. Soc. Chang. 2018, 136, 114-131. [CrossRef] 
20. Katz, B.; Wagner, J. The Rise of Innovation Districts: A New Geography of Innovation in America. Harv. Bus. Rev. 2014, 1-34. Available online: https://www.brookings.edu/wp-content/uploads/2016/07/ InnovationDistricts1.pdf (accessed on 25 September 2020).

21. Dattee, B.; Alexy, O.; Autio, E. Maneuvering in Poor Visibility: How Firms play the ecosystem game when uncertainty is high. Acad. Manag. J. 2017, 1-67. [CrossRef]

22. Mulas, V.; Minges, M.; Applebaum, H. Boosting Tech Innovation: Ecosystems in Cities. Innovations 2016, 11, 98-125. [CrossRef]

23. Russell, M.G.; Huhtamäki, J.; Still, K.; Rubens, N.; Basole, R.C. Relational capital for shared vision in innovation ecosystems. Triple Helix 2015, 2. [CrossRef]

24. Su, Y.S.; Zheng, Z.X.; Chen, J. A multi-platform collaboration innovation ecosystem: The case of China. Manag. Decis. 2018, 56, 125-142. [CrossRef]

25. Zahra, S.A.; Nambisan, S. Entrepreneurship and strategic thinking in business ecosystems. Bus. Horiz. 2012, 55, 219-229. [CrossRef]

26. de Vasconcelos Gomes, L.A.; Salerno, M.S.; Phaal, R.; Probert, D.R. How entrepreneurs manage collective uncertainties in innovation ecosystems. Technol. Forecast. Soc. Chang. 2018, 128, 164-185. [CrossRef]

27. Lubik, S.; Garnsey, E. Entrepreneurial innovation in science-based firms: The need for an ecosystem perspective. In Handbook of Research on Small Business and Entrepreneurship; Chell, E., Karataş-Özkan, M., Eds.; Edward Elgar: Cheltenham, UK, 2014; pp. 599-633.

28. Pellinen, A.; Ritala, P.; Järvi, K.; Sainio, L.M. Taking initiative in market creation-A business ecosystem actor perspective. Int. J. Bus. Environ. 2012, 5, 140. [CrossRef]

29. Meyer-Larsen, N.; Hauge, J.; Baalsrud, M.R.; Hamadache, K.; Aifadopoulou, G.; Forcolin, M.; Roso, V.; Tsoukos, G.; Westerheim, H. Accelerating the Innovation Uptake in Logistics. In Innovative Methods in Logistics and Supply Chain Management; Blecker, T., Kersten, W., Ringle, C.M., Eds.; Epubli: Berlin, Germany, 2014; Volume 19.

30. Warnke, P.; Koschatzky, K.; Som, O.; Stahlecker, T.; Nabitz, L.; Braungardt, S.; Cuhls, K.; Dönitz, E.; Güth, S.; Plötz, P.; et al. Opening Up the Innovation System Framework Towards New Actors and Institutions. Innov. Syst. Policy Anal. 2016, 49, Fraunhofer ISI, Karlsruhe. Available online: https: //www.econstor.eu/handle/10419/129191 (accessed on 9 September 2020).

31. Wilkinson, P. A brief history of serious games. In Entertainment Computing and Serious Games; van der Spek, E., Göbel, S., Do, E.Y.-L., Clua, E., Baalsrud, H.J., Eds.; Springer International Publishing AG: Berlin/Heidelberg, Germany, 2016; pp. 17-41.

32. D'Angour, A. Plato and Play: Taking Education Seriously in Ancient Greece. Am. J. Play 2013, 5, $293-307$.

33. Abt, C.C. Serious Games; Viking Press: New York, NY, USA, 1970.

34. Duke, R.D. Gaming: The Future's Language; SAGE Publications Inc., John Wiley \& Sons: New York, NY, USA, 1974.

35. Mayer, I.S. The Gaming of Policy and the Politics of Gaming: A Review. Simul. Gaming 2009, 40, 825-862. [CrossRef]

36. Lukosch, H.K.; Bekebrede, G.; Kurapati, S.; Lukosch, S.G. A Scientific Foundation of Simulation Games for the Analysis and Design of Complex Systems. Simul. Gaming 2018, 49, 279-314. [CrossRef]

37. Constantinescu, T.; Devisch, O.; Huybrechts, L. Civic Participation: Serious Games and Spatial Capacity Building. In Proceedings of the MEDIA CITY 5 International Conference, Plymouth, UK, 3 May 2015; pp. 179-263.

38. Olejniczak, K.; Wolański, M.; Widawski, I. Regulation crash-test: Applying serious games to policy design. Policy Des. Pract. 2018, 1, 194-214. [CrossRef]

39. Patricio, R. A gamified approach for engaging teams in corporate innovation and entrepreneurship. World J. Sci. Technol. Sustain. Dev. 2017, 14, 254-262. [CrossRef]

40. Oonk, M. Smart Logistics Corridors and the benefits of Intelligent Transportation Systems. I. In Towards Innovative Freight and Logistics, Science, Society and New Technologies Series, Research for Innovative Transports Set; Wiley: Hoboken, NJ, USA, 2016.

41. van Pelt, S.C.; Haasnoot, M.; Arts, B.; Ludwig, F.; Swart, R.; Biesbroek, R. Communicating climate (change) uncertainties: Simulation games as boundary objects. Environ. Sci. Policy 2015, 45, 41-52. [CrossRef] 
42. Hidayatno, A.; Zulkarnain; Hasibuan, R.G.; Wardana Nimpuno, G.C.; Destyanto, A.R. Designing a serious simulation game as a learning media of sustainable supply chain management for biofuel production. Energy Procedia 2019, 156, 43-47. [CrossRef]

43. Blöchl, S.J.; Michalicki, M.; Schneider, M. Simulation Game for Lean Leadership-Shopfloor Management Combined with Accounting for Lean. Procedia Manuf. 2017, 9, 97-105. [CrossRef]

44. Van den Hoogen, J.; Meijer, S. Gaming and Simulation for Railway Innovation: A Case Study of the Dutch Railway System. Simul. Gaming 2014, 46, 489-511. [CrossRef]

45. Kurapati, S.; Kourounioti, I.; Lukosch, H.; Tavasszy, L.; Verbraeck, A. Fostering sustainable transportation operations through corridor management: A simulation gaming approach. Sustainability 2018, 10, 455. [CrossRef]

46. Bekebrede, G.; Lo, J.; Lukosch, H. Understanding Complex Systems Through Mental Models and Shared Experiences: A Case Study. Simul. Gaming 2015, 46, 536-562. [CrossRef]

47. Witte, P.; Slack, B.; Keesman, M.; Jugie, J.H.; Wiegmans, B. Facilitating start-ups in port-city innovation ecosystems: A case study of Montreal and Rotterdam. J. Transp. Geogr. 2018, 71, 224-234. [CrossRef]

48. Port of Rotterdam, Facts \& Figures: A Wealth of Information. Make It Happen. Available online: https://www.portofrotterdam.com/sites/default/files/facts-and-figures-port-of-rotterdam.pdf (accessed on 25 September 2020).

49. Van der Horst, M.; Kort, M.; Kuipers, B.; Geerlings, H. Coordination problems in container barging in the port of Rotterdam: An institutional analysis. Transp. Plan. Technol. 2019, 42, 187-199. [CrossRef]

50. Roukouni, A.; Lukosch, H.; Verbraeck, A.; Zuidwijk, R. Mobilise Innovation (Mobinn): A playful Approach applied to the Transport and Logistics Sector. In Proceedings of the 50th ISAGA (International Simulation and Gaming Association) Conference: Simulation \& Gaming through Time and across Disciplines. Past and Future, Heritage and Progress, Warsaw, Poland, 26-30 August 2019; pp. 468-479.

51. Van Ark, E.J.; Duijnisveld, M.; van Eijk, E.; Janssen, R.; van Ommeren, C.; Soekroella, A. Value Case Truck Platooning-An Early Exploration of the Value of Large-Scale Deployment of Truck Platooning. TNO: Den Haag, The Netherlands, 2017, 1-100. Available online: https://repository.tudelft.nl/view/tno/uuid\% 3A770c9b7c-40f0-4036-93e8-caba19c2b311 (accessed on 25 September 2020).

52. Deelen, C. Truck Platooning. Available online: https://smartport.nl/en/project/truck-platooning/ (accessed on 5 October 2020).

53. Tavasszy, L. On the Value Case for Truck Platooning in Europe. Discussion Paper for Truck Platooning Next Level Group Meeting, a Side Event to the ITS European Congress, Glasgow, June 6, 2016. Available online: https://www.researchgate.net/publication/312116529_The_value_case_for_truck_platooning (accessed on 9 September 2020).

54. Bakermans, B.A. Truck Platooning Enablers, Barriers, Potential and Impacts; TU Delft: Delft, The Netherlands, 2016.

55. Roukouni, A.; Lukosch, H.; Verbraeck, A. Simulation games to foster innovation: Insights from the transport and logistics sector. In Neo-Simulation and Gaming Toward Active Learning, Translational Systems Sciences; Hamada, R., Soranastaporn, S., Kanegae, H., Dumrongrojwatthana, P., Chaisanit, S., Rizzi, P., Dumblekar, V., Eds.; Springer: Singapore, 2019; pp. 157-165.

56. Hagiu, A.; Wright, J. Multi-Sided Platforms. Int. J. Ind. Organ. 2015, 43, 162-174. [CrossRef]

57. Van Alstyne, M.W.; Parker, G.G.; Choudary, S.P. Pipelines, Platforms, and the New Rules of Strategy. Harv. Bus. Rev. 2016, 94, 54-62.

58. Evans, D.S.; Schmalensee, R. The Antitrust Analysis of Multi-Sided Platform Businesses; National Bureau of Economic Research: Cambridge, MA, USA, 2013.

59. SELIS. Deliverable D7.21, Living Labs Operation Learning Conclusions and Other SELIS Value Propositions, Final Version; SELIS, 2019; Available online: https://www.selisproject.eu/uploadfiles/D-721-delLL_Operation_ Learning_Conclusions_v3.0.pdf (accessed on 9 September 2020).

60. Christopher, M.; Lee, H. Mitigating supply chain risk through improved confidence. Int. J. Phys. Distrib. Logist. Manag. 2004, 34, 388-396. [CrossRef]

61. Olesen, P.B.; Hvolby, H.H. D-PI Enabling Information Sharing in a Port. In Proceedings of the Dvances in Production Management Systems. Competitive Manufacturing for Innovative Products and Services. APMS 2012. IFIP Advances in Information and Communication Technology; Emmanouilidis, C., Taisch, M., Kiritsis, D., Eds.; Springer: Berlin/Heidelberg, Germany, 2013; pp. 152-159. 
62. Macharis, C. Mobility is a serious game: A game to explore the future of mobility. In Proceedings of the Transportation Research Board 97th Annual Meeting, Washington, DC, USA, 7-11 January 2018.

63. König, A.; Kowala, N.; Wegener, J.; Grippenkoven, J. Introducing a mobility on demand system to prospective users with the help of a serious game. Transp. Res. Interdiscip. Perspect. 2019, 3, 100079. [CrossRef]

64. Harteveld, C. Triadic Game Design: Balancing Reality, Meaning and Play, 1st ed.; Springer: London, UK, 2011; ISBN 978-1-84996-157-8.

65. Bhoopalam, A.K.; Agatz, N.; Zuidwijk, R. Planning of truck platoons: A literature review and directions for future research. Transp. Res. Part B 2018, 107, 212-228. [CrossRef]

66. Janssen, G.; Zwijnenberg, H.; Blankers, I.; de Kruijff, J. Future of Transportation Truck Platooning; TNO: Delft, The Netherlands, 2015; pp. 1-36.

67. Commendatore, C. For Truck Platooning to Work, Here's What has to Happen. FleetOwner. 2018. Available online: https:/www.fleetowner.com/technology/article/21702545/for-truck-platooning-to-work-heres-whathas-to-happen (accessed on 25 September 2020).

68. Malcolm Wheatley, M.R. Time to Fall in Line. Available online: https://www.automotivelogistics.media/timeto-fall-in-line/21089.article (accessed on 5 October 2020).

69. Dutch Ministry of Infrastructure and Environment. European Truck Platooning Challenge 2016-A Fresh Perspective on Mobility and Logistics. 2016, 1-50. Available online: https://www.government.nl/documents/ leaflets/2015/10/06/leaflet-european-truck-platooning-challenge-2016 (accessed on 9 September 2020).

70. Association, E.A.M. First Cross-Border Truck Platooning Trial Successfully Completed. Available online: https://www.acea.be/press-releases/article/first-cross-border-truck-platooning-trial-successfullycompleted (accessed on 5 October 2020).

71. Roberts, J. Success of Truck Platooning Challenge Clears Way for Real-Life Convoys-Steve Phillips, CEDR. Available online: https://horizon-magazine.eu/article/success-truck-platooning-challenge-clears-way-reallife-convoys-steve-phillips-cedr.html (accessed on 5 October 2020).

72. Anastasia, R.; Rob, Z. Multi-Sided Platforms in Europe's Logistics Sector; RSM Case Development Centre: Rotterdam, The Netherlands, 2020.

73. OECD Glossary. Available online: https://stats.oecd.org/glossary/detail.asp?ID=4313 (accessed on 9 September 2020).

74. Kriz, W.C. A systemic-constructivist approach to the facilitation and debriefing of simulations and games. Simul. Gaming 2010, 41, 663-680. [CrossRef]

75. SmartPort About SmartPort. Available online: https://smart-port.nl/en/about-smartport-2/ (accessed on 9 September 2020).

76. Erasmus, U. Erasmus Port Campus. Available online: https://www.eur.nl/en/upt/news/first-erasmus-portcampus-launches-focus-digitization-ports (accessed on 9 September 2020).

77. Den Haan, R.J.; van der Voort, M.C. On evaluating social learning outcomes of serious games to collaboratively address sustainability problems: A literature review. Sustainability 2018, 10, 4529. [CrossRef]

Publisher's Note: MDPI stays neutral with regard to jurisdictional claims in published maps and institutional affiliations.

(C) 2020 by the authors. Licensee MDPI, Basel, Switzerland. This article is an open access article distributed under the terms and conditions of the Creative Commons Attribution (CC BY) license (http://creativecommons.org/licenses/by/4.0/). 